\title{
A nutrient-dependent division antagonist is regulated post-translationally by the Clp proteases in Bacillus subtilis
}

\author{
Norbert S. Hill ${ }^{1,2}$, Jason D. Zuke ${ }^{1,3}$, P. J. Buske ${ }^{1,4}$, An-Chun Chien ${ }^{1,5}$ and Petra Anne Levin ${ }^{1 *}$
}

\begin{abstract}
Background: Changes in nutrient availability have dramatic and well-defined impacts on both transcription and translation in bacterial cells. At the same time, the role of post-translational control in adaptation to nutrient-poor environments is poorly understood. Previous studies demonstrate the ability of the glucosyltransferase UgtP to influence cell size in response to nutrient availability. Under nutrient-rich medium, interactions with its substrate UDP-glucose promote interactions between UgtP and the tubulin-like cell division protein FtsZ in Bacillus subtilis, inhibiting maturation of the cytokinetic ring and increasing cell size. In nutrient-poor medium, reductions in UDPglucose availability favor UgtP oligomerization, sequestering it from FtsZ and allowing division to occur at a smaller cell mass.

Results: Intriguingly, in nutrient-poor conditions UgtP levels are reduced $\sim 3$-fold independent of UDP-glucose. $B$. subtilis cells cultured under different nutrient conditions indicate that UgtP accumulation is controlled through a nutrient-dependent post-translational mechanism dependent on the Clp proteases. Notably, all three B. subtilis Clp chaperones appeared able to target UgtP for degradation during growth in nutrient-poor conditions.
\end{abstract}

Conclusions: Together these findings highlight conditional proteolysis as a mechanism for bacterial adaptation to a rapidly changing nutritional landscape.

Keywords: Cell cycle, Cell size, Cell division, ClpP, UgtP, UDP-glucose

\section{Background}

As single-celled organisms, bacteria constantly alter their physiology to adapt to their environment. Nutrients in particular can dramatically impact bacterial growth and morphology. Escherichia coli, Salmonella, and Bacillus subtilis cells grow several times faster and are up to three times larger when cultured in nutrient-rich medium than when cultured in nutrient-poor medium [1-3]. Nutrient-dependent increases in cell size appear to be a means of accommodating the concomitant increase in macromolecular biosynthesis at faster growth rates, particularly the additional DNA generated by multifork replication $[4,5]$.

The nutrient-dependent regulation of biosynthesis has been an area of intense interest for many years.

\footnotetext{
* Correspondence: plevin@wustl.edu

${ }^{1}$ Department of Biology, Washington University, St. Louis 63130, MO, USA

Full list of author information is available at the end of the article
}

Numerous studies have explored how changes in nutrient composition and growth rate impact transcription and translation, which in large part is a response mediated via accumulation of the signaling molecule guanosine pentaphosphate ((p)ppGpp) [6-9]. Although posttranslational regulation has been implicated in adaptation to changes in growth phase (e.g. carbon starvation $[10,11])$, how fluctuations in nutritional content and growth rate impact post-translational regulation at the molecular level is poorly defined.

In previous work, we identified a class of division antagonists responsible for coordinating cell size with nutrient availability in B. subtilis and E. coli $[4,5]$. Both organisms employ unrelated, yet functionally similar, glucosyltransferases-UgtP in B. subtilis and OpgH in $E$. coli-to inhibit division and increase size during growth in carbon-rich medium [12, 13]. In both cases, binding to their substrate, UDP-glucose, stimulates interaction between UgtP and $\mathrm{OpgH}$ and the tubulin-like cell 
division protein FtsZ. The net result of these interactions is a delay the maturation of the cytokinetic ring and an increase cell size. Loss-of-function mutations in ugtP or opgH and in genes required for UDP-glucose biosynthesis reduce cell size by as much as 35\% during growth in nutrient-rich conditions.

UgtP and OpgH both have additional roles as glucosyltransferases that contribute to cell envelope biogenesis. UgtP transfers glucose from UDP-glucose to diacylglycerol to form the diglucosyl-diacylglycerol membrane anchor for lipoteichoic acid (LTA) [14]. OpgH transfers glucose from UDP-glucose to the periplasm as an initial step toward the synthesis of osmoregulated periplasmic glucans (OPGs) [15]. LTA and OPGs are proposed to have similar functions [16] based on the conservation of enzymes involved in their synthesis, their location within the cellular envelope $[17,18]$, and their contribution to osmoprotection $[13,19]$.

In B. subtilis, UDP-glucose increases UgtP's affinity for FtsZ [20]. During growth in nutrient-rich conditions UgtP is localized throughout the cytoplasm, where the largest pool of FtsZ is located, and can also be found at the cytokinetic ring and at cell poles [4]. During growth in carbon-poor conditions or when synthesis of UDPglucose is disrupted, UgtP self-assembles into large oligomers, sequestering it from FtsZ and permitting division to occur at a reduced cell size [20]. In vitro studies suggest UDP-glucose acts as a molecular rheostat, precisely modulating UgtP's affinity for itself and FtsZ to coordinate size with growth rate and nutrient availability [20]. Curiously, while the UgtP homolog in the Gram-positive pathogen Staphylococcus aureus interacts with FtsZ and other divisome proteins, it does not exhibit the same dynamic localization pattern it does in $B$. subtilis nor does it appear to make a significant contribution to cell size [17].

In addition to UDP-glucose-dependent changes in its affinity for FtsZ, UgtP is also subject to nutrientdependent changes in concentration. UgtP levels are reduced several-fold during growth in nutrient-poor conditions [4]. Defects in the UDP-glucose biosynthesis pathway have no discernable impact on the intracellular concentration of UgtP, suggesting that nutrientdependent changes in accumulation are independent of the signaling molecule [4].

The striking difference in UgtP levels, together with previous work suggesting protein turnover might be increased in nutrient-poor conditions [10], prompted us to investigate the mechanism underlying this additional layer of UgtP regulation. Here we report that UgtP nutrient-dependent accumulation is governed by a posttranslational mechanism involving all three substrate recognition components of the $B$. subtilis Clp protease system. We find that some of the clp chaperone genes are upregulated during growth in nutrient-poor medium, suggesting a possible mechanism for increased UgtP degradation under these conditions. These findings suggest an important role for conditional proteolysis in the nutrient-dependent regulation of cellular processes.

\section{Results \\ UgtP accumulation is subject to nutrient-dependent post-translational regulation}

In our initial investigation, we observed that the intracellular concentration of a UgtP-6XHis fusion protein was three to four-fold lower when cells were cultured under carbon-poor conditions, but unaffected by the absence of UDP-glucose [4]. Nutrient-dependent changes in concentration contrast strongly with FtsZ, whose levels are essentially constant across a wide range of growth conditions [21]. The net result is a reduction in the UgtP:FtsZ ratio from $\sim 1: 2$ in $\mathrm{LB}$ to as low as $\sim 1: 8$ in minimal medium based on previous calculations of absolute FtsZ and UgtP concentrations per cell $[4,22]$. To expand on this observation we measured levels of the same UgtP-His fusion across four different nutrient conditions: Lysogeny Broth [LB], S7 $50+1 \%$ glucose (minimal glucose), $\mathrm{S}_{50}+1 \%$ glycerol (minimal glycerol), and $\mathrm{S}_{50}$ $+1 \%$ sorbitol (minimal sorbitol). Under each condition, the respective mass doubling time of this strain $\left(P_{\text {ugt }} P^{-}\right.$ ugtP-his) was 22', 39', 58', and 78'.

Consistent with our previous findings, UgtP-His levels increased linearly with nutrient availability and growth rate, as evidenced by a semi-quantitative immunoblot probed with an $\alpha$-His antibody (Fig. 1). The intracellular concentration of UgtP-His was $\sim 3$-fold lower in cells cultured in minimal sorbitol, the most carbon-poor condition we examined, than in those cultured in LB, the most nutrient-rich condition examined. To control for the possibility that the His-tag was impacting the stability of UgtP-His, we also measured YFP-UgtP levels in a strain expressing the fusion protein from a xyloseinducible promoter $\left(P_{x y l}-y f p-u g t P\right)$, cultured in both LB $+0.5 \%$ xylose and minimal sorbitol $+0.5 \%$ xylose. As we observed with UgtP-His, YFP-UgtP levels were $~ 3$-fold lower in minimal sorbitol compared to LB supporting a model in which UgtP (and not the His or YFP tag) is the primary target for degradation during growth in minimal sorbitol medium (Additional file 1:Figure S1).

To determine if UgtP is subject to transcriptional or post-transcriptional modes of regulation, we generated two ugtP-lac $Z$ fusion constructs. In the first construct, a reporter for $u g t P$ transcription, the 700 base pairs immediately upstream of the ugtP start codon were fused to $l a c Z$, leaving the lac $Z$ Shine-Dalgarno sequence intact. In the second construct, a reporter for UgtP translation, lac $Z$ was fused in-frame downstream of the first 30 codons of the ugtP open reading frame that included the native ugtP Shine-Dalgarno sequence. 


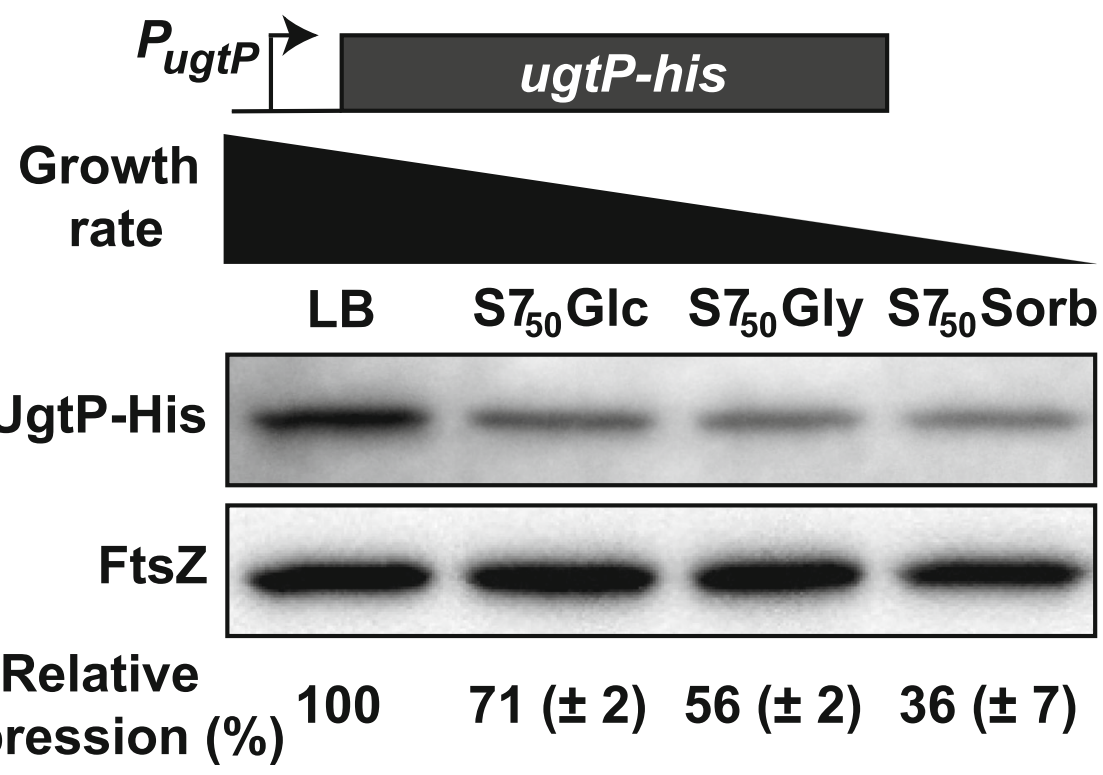

Fig. 1 UgtP accumulates only in nutrient-rich conditions. Semi-quantitative immunoblot measuring native UgtP-His levels in a range of growth conditions. PL2265 ( $P_{\text {ugtp }}$-ugtP-his) was cultured in LB $\left(\tau=22^{\prime}\right)$, minimal glucose $\left(\tau=39^{\prime}\right)$, minimal glycerol $\left(\tau=58^{\prime}\right)$, or minimal sorbitol $\left(\tau=78^{\prime}\right)$. FtsZ is shown as a loading control. Protein levels in LB are set as the reference in the relative expression below $(n=3$, error $=S D)$

lacZ expression data suggest that nutrient-dependent changes in the intracellular level of UgtP are independent of both transcriptional and translational control. In contrast to UgtP-His levels, expression of both the transcriptional and translational lac $Z$ fusions was inversely proportional to growth rate. lac $Z$ expression from the transcriptional fusion was 2-fold higher in cells cultured in minimal sorbitol than LB (Fig. 2A) and expression from the translational fusion was 4-fold higher in minimal sorbitol than LB (Fig. 2B). qRT-PCR data also indicated that ugtP expression is elevated during growth in minimal sorbitol (Fig. 2C). ugtP levels were 1.3-fold higher in minimal glucose, 1.7 -fold higher in minimal glycerol, and 2.5-fold higher in minimal sorbitol compared to LB. In all, these data strongly support a model where nutrient-dependent changes in UgtP accumulation are governed by a post-translational mechanism.

\section{The Clp proteases are responsible for UgtP degradation} under carbon-poor conditions

To understand the mechanism responsible for the post-translational regulation of UgtP, we sought to identify the protease responsible for its degradation. As an initial step, we screened B. subtilis strains defective in five well-studied proteases: YluC, CptA, $\mathrm{ClpP}, \mathrm{YvjB}$, and Lon for aberrant UgtP regulation. We rationalized that if one of these proteases were responsible for the growth rate-dependent degradation of UgtP, then UgtP would inappropriately accumulate in its absence during growth in carbon-poor conditions. For this experiment we used the $P_{x y l}$-ugtP-his construct described above to enhance our ability to detect UgtP by semi-quantitative immunoblot. During growth in LB medium and in the presence of the inducer, xylose, this construct raises intracellular UgtP levels $\sim 8.5$-fold (changing the UgtP:FtsZ ratio from $\sim 1: 2$ to $\sim 4: 1)$ and increases cell length by $\sim 22 \%[4]$. ( $P_{x y l}$ is generally insensitive to nutrient availability [21].)

Analysis of the protease-deficient strains strongly implicated ClpP in the nutrient-dependent control of UgtP accumulation. UgtP-His levels increased significantly while cultured in minimal sorbitol only in the strain defective for ClpP (Fig. 3A). UgtP-His levels were approximately 5 -fold higher during growth in minimal sorbitol in the $\triangle c l p P$ strain than in the parental strain or in the four other protease mutants. ClpP-dependent proteolysis distinguishes UgtP from FtsZ, which is insensitive to Clp-mediated proteolysis in B. subtilis [23, 24].

$\mathrm{ClpP}$ is a processive serine protease widely conserved throughout bacteria. Ineffective on its own, ClpP functions in tandem with AAA+ ATPase Clp chaperones [25]. The Clp chaperones are responsible for recognizing target proteins, unfolding them using the energy of ATP hydrolysis, and translocating the unfolded polypeptide into the ClpP proteolytic chamber $[25,26]$. In B. subtilis, there are three Clp chaperones: $\mathrm{ClpC}, \mathrm{ClpE}$, and ClpX. Since each chaperone identifies a unique set of substrates with limited target overlap, we reasoned that either $\mathrm{ClpC}, \mathrm{ClpE}$, or $\mathrm{ClpX}$ would be responsible for growth rate-dependent degradation of UgtP. To distinguish the Clp chaperone involved, we examined 

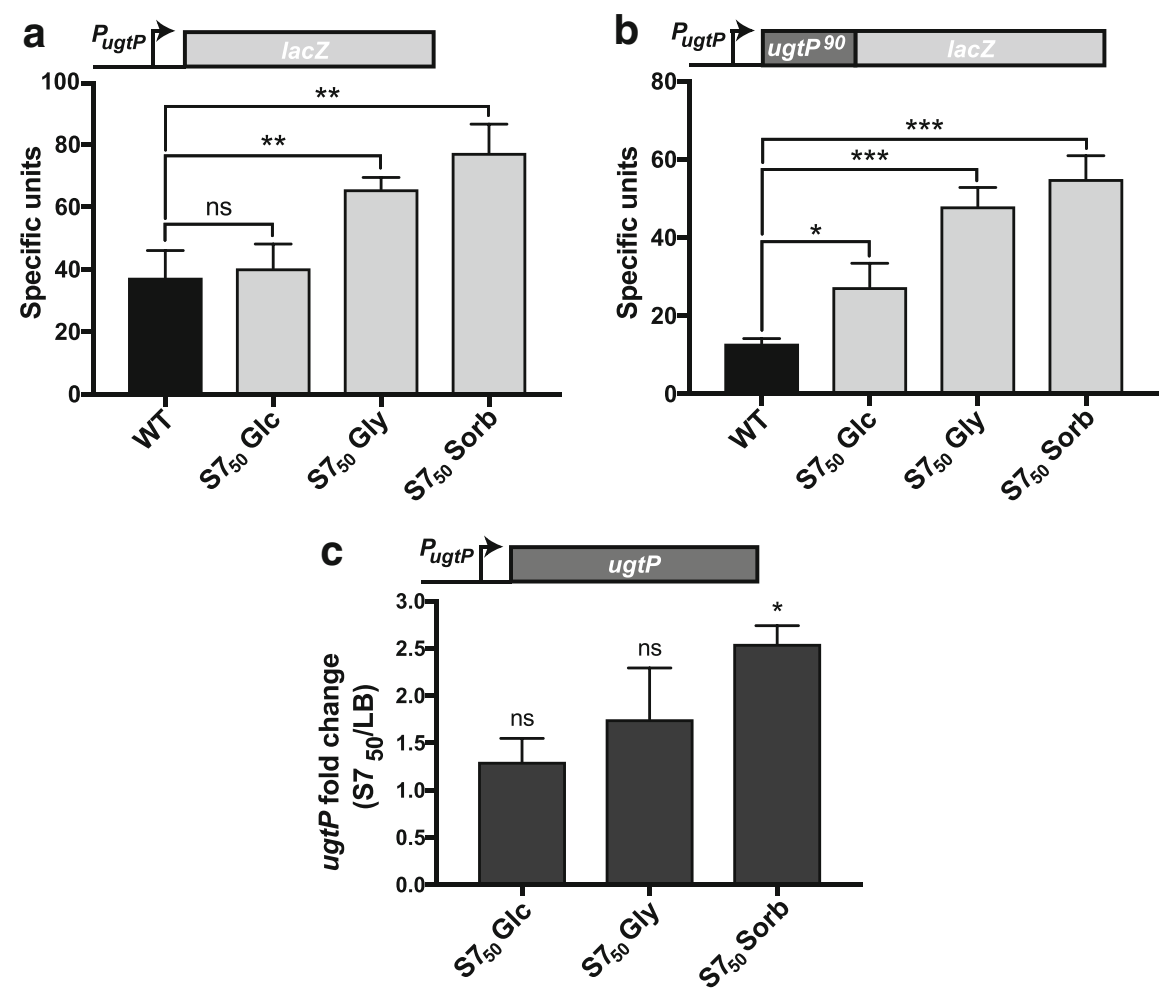

Fig. $2 \mathrm{UgtP}$ accumulation is subject to post-translational control. lacZ encoding $\beta$-galactosidase fused to either (a) 700 bp upstream of the ugtP start site $\left(P_{\text {ugt }}\right)$ to generate a transcriptional fusion (PL1967) or (b) an additional 90 bases downstream of the ugtP start codon to generate a translational fusion (PL2034). Both strains were cultured in a range of nutrient conditions to generate four different growth rates. Bars indicate mean \pm SD of specific $\beta$-galactosidase activity $(n=3)$ and an unpaired T-test was used to access significance $\left({ }^{* * *} p<0.001,{ }^{* *} p<0.01,{ }^{*} p<0.05\right.$, ns $p>0.05)$. (c) qRT-PCR measurements of ugtP expression levels. Expression in three defined media is normalized to expression in LB. Values are mean $\pm S D(n=3)$. An unpaired T-test was applied to the $\Delta C$ t values to access significance $\left({ }^{*} p<0.05, n s p>0.05\right)$

accumulation of UgtP-His from a xylose-inducible promoter in $\Delta c l p C, \Delta c l p E$, and $\Delta c l p X$ cells cultured in minimal sorbitol.

Deletion of $\operatorname{clp} C, \operatorname{clp} E$, and $\operatorname{clp} X$ alone or in pairwise combination had little impact on UgtP-His levels in minimal sorbitol. UgtP-His accumulated to levels similar to that observed in the $\triangle c l p P$ mutant only in a strain defective for all three chaperones (Fig. 3B). These data suggest that all three Clp chaperones function redundantly to control UgtP accumulation in a growth rate-dependent manner.

To confirm that the Clp proteases are indeed responsible for degradation of UgtP, as our data suggested, we employed an in vivo proteolysis assay similar to that described in [27]. Briefly, we cultured $P_{x y l}-u g t P$-his and the congenic $\triangle c l p P$ strains in minimal sorbitol with xylose to an $\mathrm{A}_{600}$ of $\sim 0.2$. We then added chloramphenicol to inhibit new protein synthesis and sampled cells every $30 \mathrm{~min}$ for $2 \mathrm{~h}$. UgtP-His levels were determined via semi-quantitative immunoblot. Consistent with UgtP being directly targeted by ClpP, UgtP-His levels decreased rapidly in $c l p P^{+}$cells over time, but were stable in the absence of the protease (Fig. 3C and Additional file 2: Figure S2).
Consistent with the Clp proteases serving as nutrientdependent regulators of protein stability, expression of $\operatorname{clp} C$ and $\operatorname{clp} E$ were elevated in minimal sorbitol (Fig. 3D). qRT-PCR indicated that expression of $c l p C$ and $c l p E$ are upregulated $>4$-fold, while $\operatorname{clpX}$ and $\operatorname{clp} P$ are marginally upregulated $(\sim 1.5$-fold) in minimal sorbitol, our poorest carbon source, relative to LB. These findings are consistent with those of the Hecker lab who observed ClpXP and $\mathrm{ClpCP}$ drive proteolysis of a large group of proteins, most notably enzymes involved in central carbon metabolism, upon glucose starvation (UgtP was not identified as a Clp substrate in this study) [10].

\section{Defects in UgtP's hexose-binding site increases susceptibility} to proteolysis in vivo

In an attempt to identify regions of UgtP required for recognition by the Clp chaperones, we screened a series of UgtP mutants for sensitivity to Clp-mediated degradation in vivo. Of particular interest were regions of UgtP that mediate interaction with UDP-glucose, FtsZ, or itself. To test the impact of UDP-glucose binding and oligomerization on Clp-dependent degradation, we employed three UgtP mutants, generated based on 

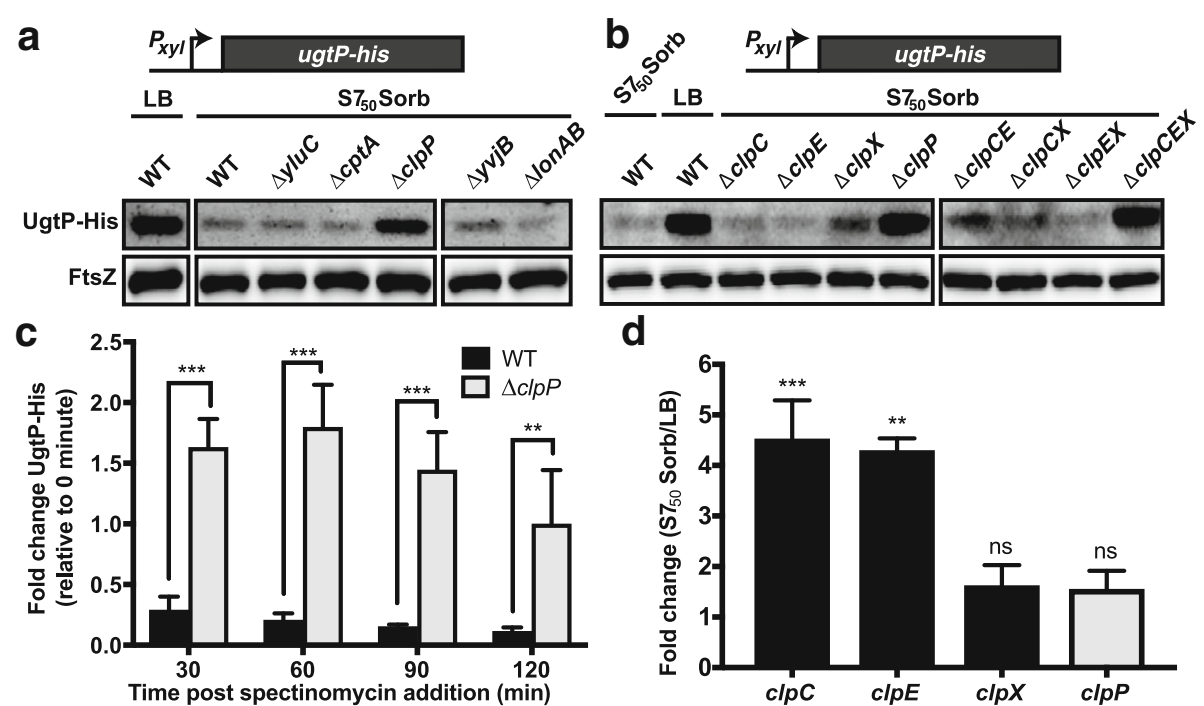

Fig. $3 \mathrm{UgtP}$ is subject to nutrient-dependent, post-translational regulation by the Clp proteases. Semi-quantitative immunoblot of UgtP-His expressed from a xylose-inducible promoter ( $P_{x y y}$-ugtP-his) in the absence of (a) 5 proteases, YluC, CptA, ClpP, YvjB, and Lon (PL2022, PL2028, PL2102, PL2032, and PL2033, BH10 as WT) or (b) single/combinatorial deletions of the Clp chaperones (ClpC, ClpE, and/or ClpX) (BH127, BH128, BH130, PL2102, $\mathrm{BH} 135, \mathrm{BH} 136, \mathrm{BH} 137, \mathrm{BH} 138)$. Cells were cultured in either $\mathrm{LB}+0.5 \%$ xylose or minimal sorbitol $+0.5 \%$ xylose, and immunoblotted against His and FtsZ. Samples shown in (a) and also for (b) were run on the same blot, but cropped during image processing. (c) Fold change in UgtP-His levels for $P_{x y}-$ - $u g t P$-his $(\mathrm{BH} 10)$ and $P_{x y}$ - $u g t P-h i s+\Delta c l p P(B H 129)$ after adding spectinomycin to inhibit translation. Cells were cultured in minimal sorbitol $+0.5 \%$ xylose, sampled every 30 min after spectinomycin addition, and subjected to immunoblotting against His antibody. Values are mean \pm SD $(n=3)$. A two-way ANOVA was used to assess differences in UgtP-His levels $\pm c l p P$ over time $(P<0.0001)$ and a Bonferroni multiple comparisons test (shown) was used to determine significance between the two strains at specific time intervals $\left({ }^{* * *} p<0.001,{ }^{* *} p<0.01\right)$. (d) qRT-PCR measurements of $c / p C, c l p E$, $c l p X$, and $c / p P$ expression in minimal sorbitol versus LB. Values are mean $\pm S D(n=4)$. An unpaired T-test was applied to the $\Delta C$ t values to access significance $\left({ }^{* * *} p<0.001\right.$, ${ }^{* *} p<0.01$, ns $p>0.05$ )

structural data from the UgtP homologue, mongalactosyldiacylglycerol (MGDG) synthase [28]: one defective in its putative uracil-binding site (URA-: F112A V117A), one defective in the putative hexose-binding site (HEX-: E306A N309A), and one in the predicted dimerization/ oligomerization domain (OLI-: I142A E146A).

All three UgtP mutants behaved as predicted based on structural and biochemical data from the MGDG synthase (Fig. 4A) [28]. Both UgtP $\mathrm{PRA}^{\mathrm{URA}}$ and $\mathrm{UgtP}^{\mathrm{HEX}-}$ are defective as sugar transferases, exhibit a punctate localization pattern during growth in nutrient-rich medium, and fail to complement a ugtP null strain for cell size, all of which is consistent with increased self-association and a loss of interaction with FtsZ [20]. In support of our model that oligomerization serves to sequester UgtP from FtsZ, during growth in the absence of UDP-glucose the putative oligomerization mutant $\left(\mathrm{UgtP}^{\mathrm{OLI}-}\right)$ exhibited less punctate (self-associated) localization (Additional file 3: Figure S3A) and antagonized division to increase cell length by more than 30\% (Additional file 3: Figure S3B).

For analysis of UgtP mutant accumulation, His-tagged versions of all three UgtP variants (URA-, HEX- and OLI-) were expressed from an ectopic locus under the control of a xylose-inducible promoter in a ugtP null background. UgtP mutant accumulation under nutrientrich (LB) and carbon-poor conditions (minimal sorbitol) was monitored by semi-quantitative immunoblot in early exponential phase. For reasons that are unclear, both

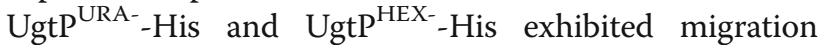
patterns different from wild type UgtP-His when separated by SDS-PAGE prior to immunoblotting (Fig. 4). This difference may reflect conformational changes in mutant protein structure.

Of the three mutants, only $\mathrm{UgtP}^{\mathrm{HEX}-}-\mathrm{His}$ exhibited ClpP-dependent differential in accumulation compared to wild type UgtP-His, suggesting hexose binding might protect UgtP from proteolysis. UgtP ${ }^{\mathrm{HEX}-}$ - His accumulated to only $\sim 35 \%$ of UgtP-His (WT) levels during growth in LB (Fig. 4B). Even in minimal sorbitol, Ugt$\mathrm{P}^{\mathrm{HEX}-}$-His levels were $\sim 65 \%$ of UgtP-His (Fig. $4 \mathrm{C}$ ). Ugt$\mathrm{P}^{\mathrm{URA}^{-}}$-His and $\mathrm{UgtP}^{\mathrm{OLI}}{ }^{-}$-His were indistinguishable from wild type UgtP-His with regard to ClpP-dependent changes in accumulation, arguing against a role for interaction with FtsZ or homo-oligomerization in shielding UgtP from Clp recognition. Importantly, each of the constructs exhibited congruent mRNA levels measured by qRT-PCR and $\mathrm{UgtP}^{\mathrm{HEX}-}$-His is at WT levels in a $\Delta c l p P$ background strain in both LB and minimal sorbitol, indicating that the change in stability is directly due to ClpPmediated degradation (Additional file 4: Figure S4).

Together these data suggest that interaction with the hexose moiety of UDP-glucose, which we have measured 


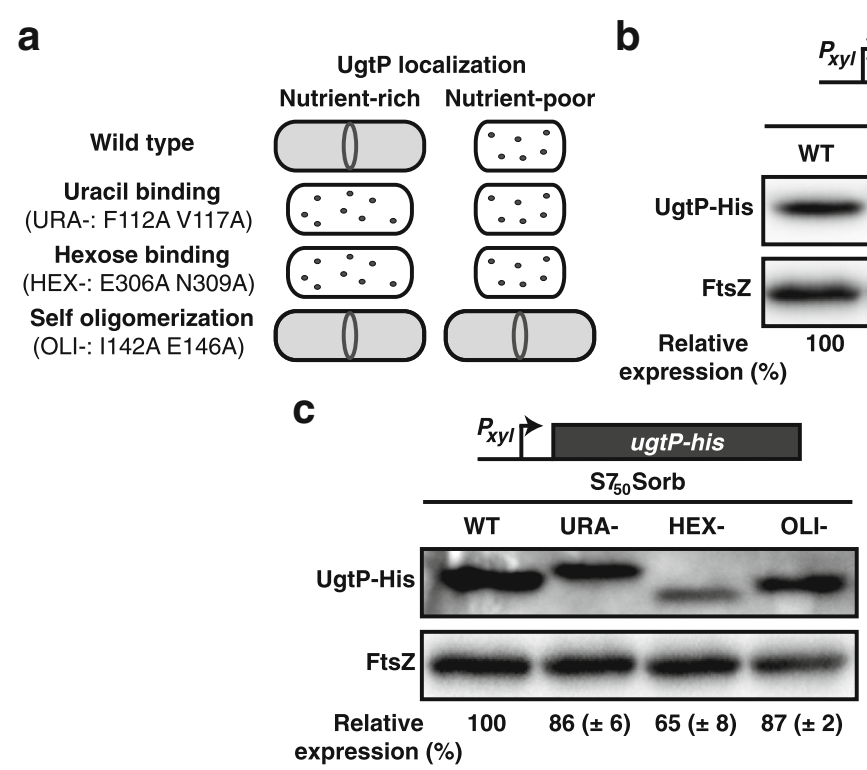

Fig. 4 Mutations in UgtP's putative hexose-binding site enhance susceptibility to proteolysis in vivo. (a) A schematic representation of YFP-UgtP localization and cell size for wild type, uracil-binding (URA-), hexose-binding (HEX-), and self-oligomerization (OLI-) mutants in either LB or minimal sorbitol (Additional file 3:Figure S3 \& [20]). UgtP-His variants BH736 (WT), BH742 (URA-), BH752 (HEX-), BH740 (OLI-) were cultured in either (b) LB $+0.5 \%$ xylose or (c) minimal sorbitol $+0.5 \%$ xylose and subjected to semi-quantitative immunoblotting against His and FtsZ (loading control) antibodies. Relative expression compared to WT $(\mathrm{BH} 736) \mathrm{UgtP}-\mathrm{His}$ is shown $(n=3$, error $=\mathrm{SD})$

as being more prevalent when cultured in nutrient-rich conditions (Additional file 5: Figure S5), may provide some protection from Clp-mediated proteolysis. At the same time, however, this observation is inconsistent with our previous observation that UgtP accumulation is independent of UDP-glucose synthesis [4], a point we address in the discussion.

\section{UgtP is targeted by ClpXP for proteolysis in vitro}

To clarify whether Clp recognition of UgtP is direct or reliant on a nutrient-dependent adaptor protein, we next determined if UgtP could be degraded directly by ClpXP in vitro. Although our genetic data indicate all three Clp chaperones are capable of degrading UgtP (Fig. 3B), we focused on $\mathrm{ClpX}$ as the most prevalent chaperone (there are an estimated $1400 \mathrm{ClpX}, 250 \mathrm{ClpC}$, and $100 \mathrm{ClpE}$ hexamers per cell during growth in LB) [29].

For these experiments, we expressed and purified $\mathrm{ClpX}$ and ClpP as previously described and a His-UgtP we constructed for this study [24]. We employed the well-characterized ClpXP substrate Spx [30] as a positive control, and a non-targeted protein, Thioredoxin-His, as a negative control. As expected, Spx was subject to robust ATP-dependent ClpXP mediated degradation, while Thioredoxin-His was retractile to ClpXP proteolysis (Additional file 6: Figure S6). Due to the size-similarity between His-UgtP and ClpX used in the degradation assays (44 kDa vs $46 \mathrm{kDa}$ ), we could not distinguish between the two when separated by standard SDS-PAGE.
Instead, we employed a monoclonal anti-His antibody to distinguish between His-UgtP and ClpX via immunoblot. Please note that because we detected UgtP by immunoblot and the anti-His antibody (monoclonal $\mathrm{THE}^{\mathrm{m}}$ antibody, Genscript) interacted strongly with nanogram amounts of the His-UgtP fusion protein, we found it necessary to utilize significantly lower concentrations of His-UgtP relative to the Spx and Thioredoxin-His control proteins to remain in linear range. While His-UgtP levels were monitored by immunoblot, Spx and Thioredoxin-His were monitored by Coomassie staining.

Consistent with our genetic analysis, in vitro data strongly support a model in which UgtP is degraded by ClpXP facilitated through a direct interaction between this Clp complex and UgtP (Fig. 5A). Incubating purified His-UgtP with the ClpXP complex without ATP resulted in minimal degradation (13\%). In stark contrast, when ATP was added to reactions $88 \%$ of His-UgtP was proteolyzed. Though the possibility of contaminating nonspecific ATP-dependent proteases in the purified protein preparations contributing to the observed His-UgtP degradation exists, we did not observe any degradation of our negative control, Thioredoxin-His (Additional file 6: Figure S6).

Based on our in vivo data supporting a model in which hexose binding may shield UgtP from Clp-mediated proteolysis (Fig. 4), we speculated that adding UDP-glucose or simply glucose to the ClpXP proteolysis assays might hinder UgtP degradation. To test this model we added 


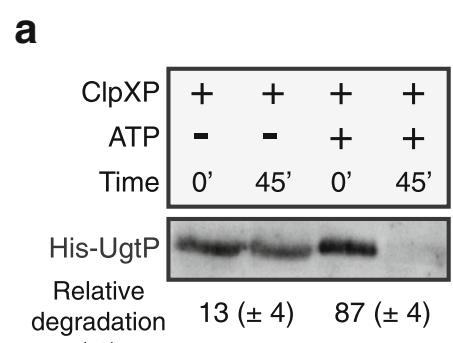

(\%)

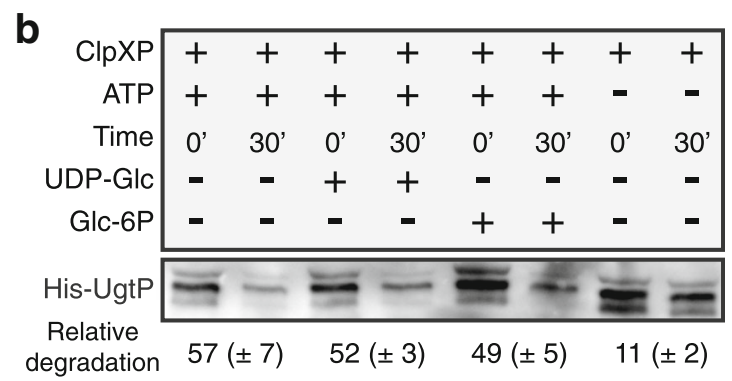

(\%)

Fig. 5 ClpXP targets UgtP for proteolysis in vitro independent of UDP-glucose. (a) Immunoblot of purified His-UgtP after incubation with purified ClpXP. Reactions consisting of $3 \mu \mathrm{M}$ ClpX, $6 \mu \mathrm{M}$ ClpP, $3 \mu \mathrm{M}$ His-UgtP, and $5 \mathrm{mM}$ ATP were incubated for $45 \mathrm{~min}$ at room temperature. ClpXP substrate controls are shown in Additional file 6: Figure S6. (b) In vitro ClpXP cleavage assay \pm UDP-glucose or glucose-6P. The assay used $3 \mu \mathrm{M}$ ClpX, $6 \mu \mathrm{M}$ ClpP, $3 \mu \mathrm{M}$ His-UgtP, 5 mM ATP, and 2 mM of either UDP-glucose or glucose-6P. a-His was used to visualize His-UgtP levels by immunoblot. Each cognate set was used to gauge relative degradation (\%) as shown below ( $n=3$, error = SD)

UDP-glucose or glucose 6-phosphate in excess to the ClpXP in vitro proteolysis reactions described above. However, we saw no difference in UgtP proteolysis in the presence of either sugar (Fig. 5B).

\section{Clp-mediated UgtP degradation during growth in minimal sorbitol medium does not significantly impact cell size or diglucosyl-diacylglycerol production}

In an effort to illuminate the potential "rationale" for Clp mediated degradation of UgtP during growth in carbon-poor medium we examined the impact of Clp activity on cell size and production of diglucosyldiacylglycerol (DGD), the anchor for LTA. UgtP exhibits a high affinity for FtsZ (38 nM) even in the absence of UDP-glucose [20]. Nutrient-dependent degradation may thus serve as an additional control to prevent UgtPmediated division inhibition during growth in carbonpoor conditions.

For these experiments, we took advantage of two strains capable of producing a range of UgtP concentrations in minimal sorbitol: BH736 ( $\Delta u g t P ; P_{x y l}$-ugtP-his)

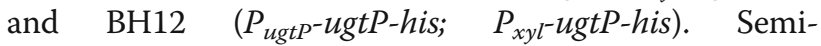
quantitative immunoblots indicate that non-induced BH736 produces no detectible UgtP-His, induced BH736 and non-induced $\mathrm{BH} 12$ produce similar levels of UgtPHis, and induced $\mathrm{BH} 12$ produces approximately $60 \%$ more UgtP-His than BH12 non-induced (Additional file 7: Figure S7). If cell size under carbon-poor conditions is sensitive to UgtP concentration, then we would expect to see a gradient of cell sizes with cell size increasing in proportion to UgtP concentration. We opted not to measure the impact of ClpP on cell size since $c l p P$ is highly pleotropic and deletion could feasibly alter cell length independent of UgtP degradation.

Somewhat surprisingly, we did not observe a significant difference in cell size between strains regardless of the presence of xylose. Average cell size was not significantly different between any set of conditions, including the UgtP-null (BH736 -xylose) and UgtP-overexpression conditions (BH12 + xylose) (Table 1, $p=0.28$ ). Additionally, cell size distributions for each condition are not obviously different from one another (Fig. 6A). These data fail to support a model in which Clp-mediated UgtP degradation is important for maintaining cell size in carbon-poor medium.

Another possible explanation for the degradation of UgtP in carbon-poor conditions is the preservation of intracellular glucose by curtailing production of UgtP's product, diglucosyldiacylglycerol [14]. To test this possibility we measured DGD levels in wild type and $\Delta c l p P$ strains, as well as their isogenic $P_{x y l}$-ugtP counterparts, cultured in minimal sorbitol (with xylose added when growing $P_{x y l}$-ugtP strains). Briefly, we purified membranes from these strains, performed a methanol:chloroform lipid extraction, separated the lipids using thinlayer chromatography, stained for DGD using iodine gas, and quantified DGD. Lipids were also extracted from $\Delta u g t P$ cells for use as a negative control.

Despite the 3-fold difference in UgtP concentration, DGD levels were not significantly different between WT/ $\Delta c l p P$ cells $(p=0.78)$ or induced $P_{x y l}-u g t P$ cells $\pm \operatorname{clpP}(p$ $=0.30)$ (Fig. 6B). As expected, $\Delta u g t P$ cells produced no detectible DGD (Additional file 8: Figure S8). These data suggest that while UgtP is necessary for DGD production, degradation of UgtP via the Clp proteases is irrelevant for modulating DGD concentration. It is therefore unlikely that degradation of UgtP occurs in carbon-poor conditions as a means of conserving glucose, as production of glucose-rich DGD is not affected by UgtP degradation.

\section{Discussion}

Our results indicate UgtP accumulation is controlled in a nutrient-dependent manner via a post-translational, Clp-dependent mechanism. This additional layer of regulation governing UgtP activity, distinct from UDPglucose-mediated changes in UgtP's affinity for itself and 
Table 1 Cell length in response to differential UgtP levels in minimal sorbitol

\begin{tabular}{|c|c|c|c|}
\hline Strain & $\begin{array}{l}\text { Relative UgtP } \\
\text { Expression }\end{array}$ & $\begin{array}{l}\text { Average } \\
\text { Cell Length }[\mu \mathrm{m}]\end{array}$ & $\begin{array}{l}\text { Change in } \\
\text { Length (\%) }\end{array}$ \\
\hline $\begin{array}{l}\text { BH736 - xylose } \\
\text { (AugtP; } P_{x y /} \text {-UgtP-his) }\end{array}$ & 0 & $2.63 \pm 0.27$ & Reference \\
\hline $\begin{array}{l}\text { BH736 + xylose } \\
\text { (AugtP; } P_{\text {xyl- }} \text {-ugtP-his) }\end{array}$ & $99 \pm 45$ & $2.72 \pm 0.11$ & $+3.4 \%$ \\
\hline $\begin{array}{l}\left(P_{\text {ugtp }} \text {-ugtP-his; } P_{x y l} \text {-ugtP-his }\right) \\
\mathrm{BH} 12-\text { xylose }\end{array}$ & $100 \pm 24$ & $3.07 \pm 0.20$ & $+16.7 \%$ \\
\hline $\begin{array}{l}\text { (Pugtp-ugtP-his; } P_{x y l} \text {-ugtP-his) } \\
\text { BH12 + xylose }\end{array}$ & $155 \pm 33$ & $2.95 \pm 0.25$ & $+12.2 \%$ \\
\hline
\end{tabular}

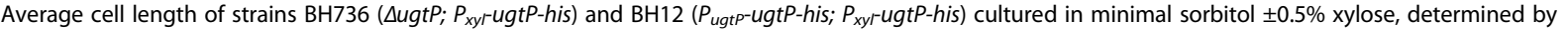
measuring the distance between the mid-points of adjacent cell wall septa $(n=600$, error $=S D)$. Relative UgtP expression is demonstrated in Additional file 7 : Figure S7

FtsZ, ensures that active UgtP accumulates only under nutrient-rich growth conditions when it antagonizes cell division. While there are several prominent examples of conditional proteolysis coupled to growth phase [31-33], there are only a handful of examples in which proteolysis has been linked to growth rate and/ or nutrient availability. Two such examples are from the Narberhaus lab: 1) The DNA-binding replication inhibitor CspD is selectively proteolyzed by the Lon protease during growth in nutrient-rich medium [34] and 2) LpxC, a deacetylase involved in lipid A biosynthesis, is degraded only when cultured at slower growth rates by the protease FtsH [35].

We were somewhat surprised by our finding that UgtP proteolysis in vivo is accomplished via the redundant activity of ClpCP, ClpEP, and ClpXP (Fig. 3B). While ZapC is recognized and degraded by ClpXP and ClpAP in $E$. coli, to our knowledge UgtP is the first published example of a Clp substrate recognized by all the Clp chaperone proteins in B. subtilis [36]. Further, we find that genes encoding two of the $c l p$ chaperones, $\operatorname{clp} C$ and $\operatorname{clpE}$, are expressed at higher levels during slower growth, which likely contributes toward the growth medium-dependent regulation of UgtP (Fig. 3D). It is noteworthy that ClpX, previously identified as a direct inhibitor of FtsZ assembly in B. subtilis independent of its role in proteolysis, also modulates the stability of an entirely different FtsZ inhibitor [24].

Since AAA+ proteases exhibit distinct substratebinding repertoires with only minor overlap in target specificity [37], it is curious how and why all three Clp chaperones are able to target UgtP. These chaperones either recognize unstructured peptide sequence tags (known as degrons) within a client protein or adaptor proteins bound to target substrates. ClpC exclusively uses adaptor proteins (MecA, $\mathrm{YpbH}$, and $\mathrm{McsB}$ ) to recognize substrate as well as to promote the activation of the ClpC hexamer [38-41]. Although ClpXP is capable of degrading UgtP in vitro (Fig. 5), we were unable to identify putative degrons for any of the three Clp chaperone proteins within the UgtP primary sequence through comparison with other verified and putative $B$. subtilis Clp substrates [10, 42, 43]. It thus remains an open question whether ClpXP, ClpCP, and ClpEP share a common degron or adaptor protein, or use distinct mechanisms, to target UgtP for degradation.

UgtP degradation was enhanced in vivo by two point mutations (E306A N309A) in its putative hexosebinding site suggesting ligand binding might afford some protection from ClpP-specific proteolysis (Fig. 4). While there is precedent in both prokaryotic and eukaryotic systems of small molecule ligands governing proteolytic susceptibility [44-46], our data do not cohesively support that UDP-glucose shields UgtP from degradation. Neither defects in UDP-glucose biosynthesis [4] nor mutations disrupting the putative nucleotide binding site (URA-, F112A V117A) had an impact on UgtP accumulation (Fig. 4). Instead, these data suggest ligand binding is largely irrelevant to UgtP stability and the hexosebinding mutation (E306A N309A) may simply lead to a conformation that exposes a Clp recognition sequence. Although we are unaware of any literature supporting a negative relationship between $c l p$ expression or activity and cell size, enrichment of the Clp proteases-particularly $\mathrm{ClpC}$ and $\mathrm{ClpE}$ - under nutrient-poor conditions as the most parsimonious, albeit still theoretical, explanation for UgtP degradation under these conditions (Fig. 3D).

\section{Conclusions}

As a whole, our data point to UgtP being subject to an elaborate set of multilayered controls. Not only is it unclear why three Clp chaperones would be needed for UgtP degradation in minimal medium, it is also not readily apparent why a carbon-starved cell would spend energy to transcribe and translate ugtP only to immediately have it proteolyzed, consuming ATP at each step. We were unable to identify a phenotypic explanation for the nutrient-dependent degradation of UgtP. Given the myriad of conditions under which B. subtilis is able to 


\section{a}

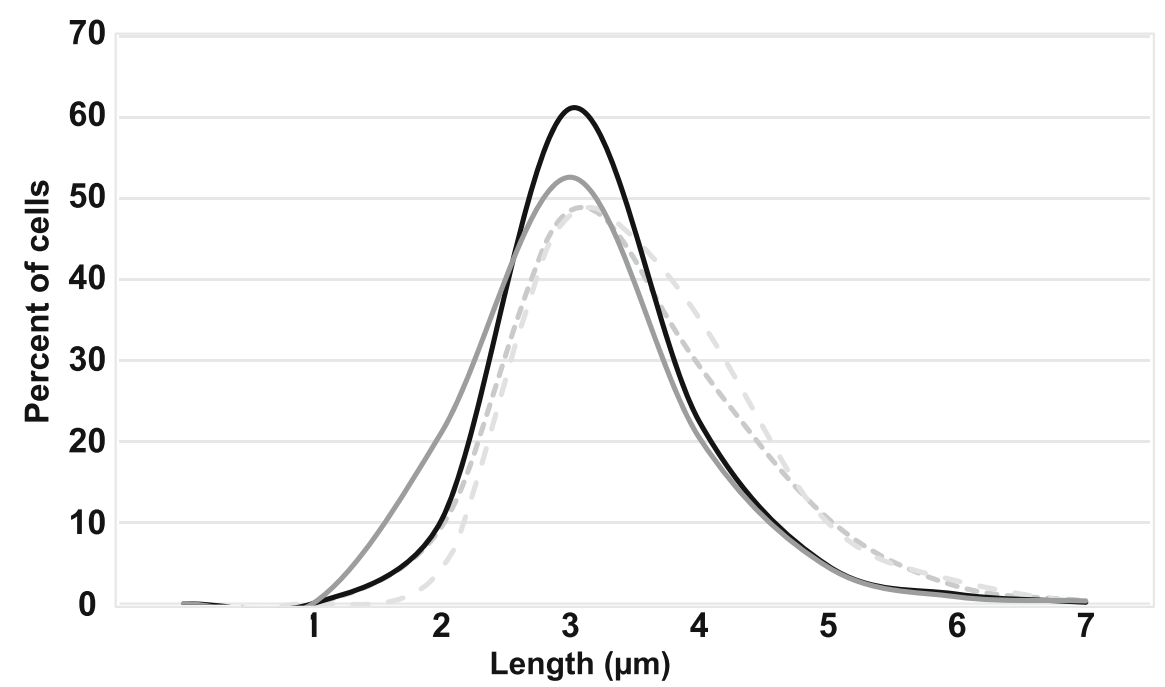

b

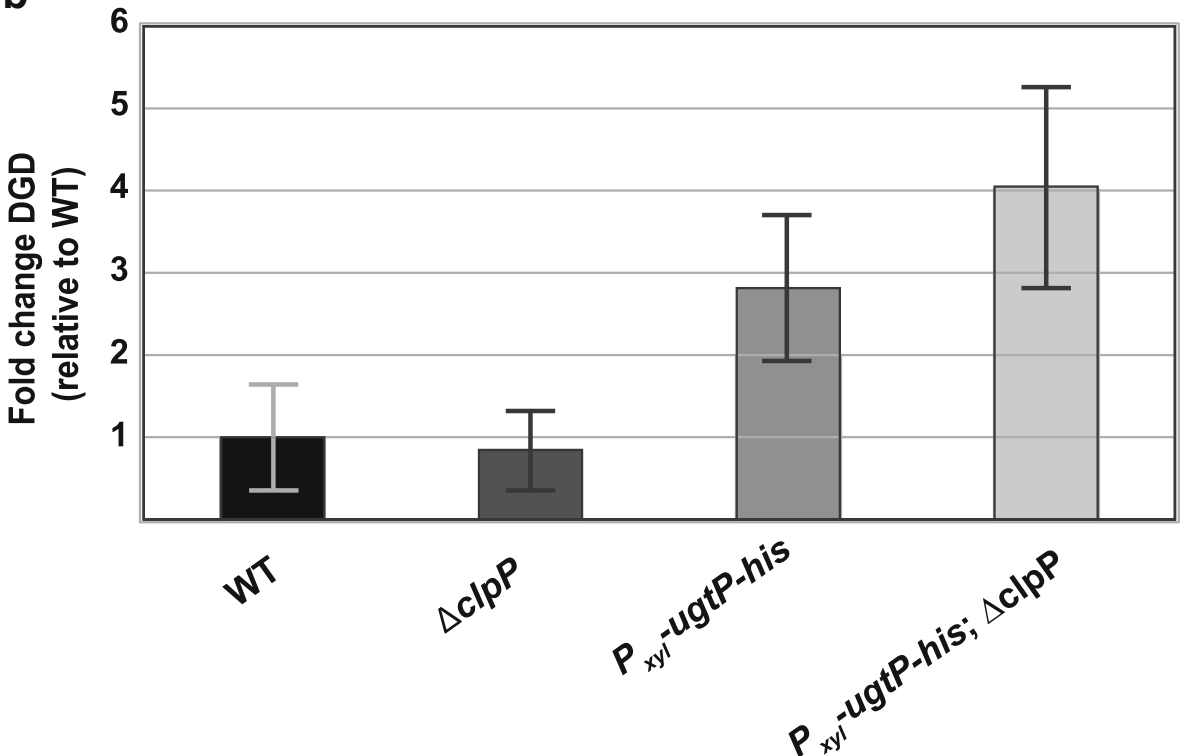

Fig. 6 UgtP levels do not significantly affect cell length or diglucosyl-diacylglycerol levels in carbon-poor media. (a) Cell length distributions of strains BH736 ( $\left(\right.$ ugtP; $P_{x y l}$-ugtP-his) and BH12 ( $P_{\text {ugtp }}$-ugtP-his; $P_{x y l}$-ugtP-his) cultured in minimal sorbitol $\pm 0.5 \%$ xylose, determined by measuring the distance between the mid-points of adjacent cell wall septa $(n=600$, error $=S D)$. (b) Relative diglucosyl-diacylglycerol concentrations of lipid

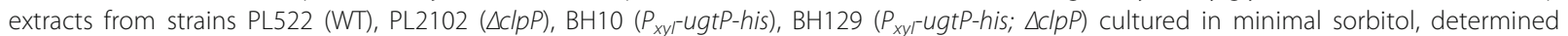
by thin layer chromatography and subsequent densitometric analysis of separated lipids $(n=3$, error $=S D)$

grow, it may very well be that we are looking in the wrong place and for the wrong phenotypes. Alternatively, UgtP may simply be one of a large cohort of proteins that have a shorter half-life during growth in carbon-poor conditions [47]. If so, growth mediumdependent changes in Clp protease activity may simply serve as a crude means of supporting B. subtilis' uncanny ability to adapt rapidly to a wide range of environments while ensuring cells retain a relatively robust supply of biosynthetic building blocks even during growth in carbon-poor conditions.

\section{Methods}

\section{Strains and general methods}

All B. subtilis strains are derivatives of JH642 [48]. Details of their construction and a list of strains used for this study are described in (Additional file 9 and Additional file 10: Table S1). All cloning was done using the E. coli strain AG1111 [49]. Either Vent (NEB) or Phusion (NEB) DNA polymerases were used for PCRs. Cells were cultured in either Lysogeny Broth (LB) or minimal S7 50 defined media [50] supplemented with either $1 \%$ glucose, glycerol, or sorbitol as carbon sources 
and appropriate amino acid supplements. For strains containing $\triangle c l p P$ or $\triangle c l p C E X$, cells were always first cultured in LB prior to growth in other growth media.

\section{Semi-quantitative immunoblotting}

Bacterial cells cultured to $A_{600} 0.20-0.40$ were lysed by centrifuging $1 \mathrm{~mL}$ of culture then re-suspending in $50 \mu \mathrm{L}$ lysis buffer $\left(20 \mathrm{mM}\right.$ tris $\mathrm{pH} 8.0,12.5 \mathrm{mM} \mathrm{MgCl}_{2}$, $1 \mathrm{mM} \mathrm{CaCl}_{2}, 2 \mathrm{mg} / \mathrm{mL}$ lysozyme, $1 \mathrm{X}$ Halt ${ }^{\mathrm{tw}}$ Protease Inhibitor Cocktail), incubating $10 \mathrm{~min}$ at $42{ }^{\circ} \mathrm{C}$, then adding SDS to $1 \%(v / v)$. Laemmli buffer was added to $1 \mathrm{X}$, lysates were incubated $10 \mathrm{~min}$ at $100{ }^{\circ} \mathrm{C}$, then lysate was normalized to OD and subjected to SDS-PAGE. Proteins were transferred to PVDF membranes using Bio-Rad Trans-Blot ${ }^{\ominus}$ Turbo $^{\text {tw }}$ instrument as described on pg. 15 of the operation manual. Subsequent to transfer, but prior to blocking PVDF membranes were stained with $1 \mathrm{X}$ Ponceau $\mathrm{S}$ solution in 5\% acetic acid for $5 \mathrm{~min}$ and total protein per lane used as a loading control [51]. Membranes were then blocked with 5\% nonfat milk in PBS for $1 \mathrm{~h}$.

Two different Anti-His antibodies to detect His-tagged UgtP were employed in this study: 1) His-probe monoclonal antibody (Santa Cruz Biotechnology) used at 1:1000 (used in Fig. 3), and 2) monoclonal $\mathrm{THE}^{\mathrm{m}} \mathrm{His}$ Tag (Genscript) $\alpha$-His antibodies incubated at 1:1000. Rabbit polyclonal (Genscript) $\alpha$-GFP antibodies incubated (at 1:1000) were used to detect YFP-tagged UgtP. FtsZ was detected using an affinity-purified polyclonal rabbit $\alpha$-FtsZ antibody (at 1:5000) [52]. Cognate goat $\alpha$ rabbit or goat $\alpha$-mouse (Genscript) HRP secondary antibodies were used (at 1:5000). The membranes were developed using ECL substrate (Bio-Rad \#1705060) and imaged using a Li-COR Odyssey FC instrument that detected saturation and autocorrected exposure time. Loading was first normalized to cell density measured by $\mathrm{A}_{600}$, then total protein per lane was calculated using Ponceau-S prior to blocking. Blot density was quantified using Image $(\mathrm{NIH})$ by subtracting background and normalizing to total protein (Ponceau $S$ staining). In some cases, FtsZ is shown as the loading control because it was largely invariant with Ponceau-S staining.

\section{In vivo UgtP degradation assay}

Protocol was adapted from [27]. Strains were cultured in $5 \mathrm{~mL} \mathrm{LB}+0.5 \%$ xylose at $37{ }^{\circ} \mathrm{C}$ with shaking until $\mathrm{A}_{600}=0.20-0.40$. These cultures were then diluted into $20 \mathrm{~mL}$ minimal sorbitol $+0.5 \%$ xylose to $\mathrm{A}_{600}=$ 0.005 . Once $\mathrm{A}_{600}$ reached $0.20-0.40$, spectinomycin was added to $200 \mu \mathrm{g} / \mathrm{mL}$. Cultures were sampled $(1 \mathrm{~mL})$ at $0,30,60,90$, and $120 \mathrm{~min}$ after spectinomycin addition, and the samples were frozen at $-80{ }^{\circ} \mathrm{C}$ for future use. These samples were then subjected to semi-quantitative immunoblotting for UgtP-His, the protein was quantified using Image $(\mathrm{NIH})$ and processed in Microsoft Excel.

\section{$\beta$-galactosidase activity in liquid cultures}

Specific activity was calculated essentially as described in [53]. Strains encoding lac $Z$ fusions were cultured at $37^{\circ} \mathrm{C}$ to early/mid-log $\left(\mathrm{A}_{600} 0.30-0.40\right)$. Prior to sampling, the cultures were diluted $1: 2$ in their respective medium and absorbance at $\mathrm{A}_{600}$ was recorded. $30 \mu \mathrm{l}$ of toluene and $30 \mu \mathrm{l}$ of a $0.1 \%$ sodium dodecyl sulfate solution were added to $2 \mathrm{ml}$ of bacterial culture to permeabilize cells. Incubating cells at $37{ }^{\circ} \mathrm{C}$ for $45 \mathrm{~min}$ then evaporated the toluene. Cells were then mixed with Z-buffer (60 $\mathrm{mM} \mathrm{Na} \mathrm{NPO}_{4}, 40 \mathrm{mM}$ $\mathrm{NaH}_{2} \mathrm{PO}_{4}, 10 \mathrm{mM} \mathrm{KCl}, 1 \mathrm{mM} \mathrm{MgSO} 4,50 \mathrm{mM} \beta-$ mercaptoethanol) and tubes were incubated at $25{ }^{\circ} \mathrm{C}$ for $5^{\prime}$. Reactions were started by adding $0.25 \mathrm{ml}$ of $0.4 \%$ o-nitrophenol- $\beta$-galactoside in Z-buffer and stopped by adding $0.5 \mathrm{ml}$ of $1 \mathrm{M} \mathrm{Na}_{2} \mathrm{CO}_{3} \cdot \mathrm{A}_{420}$ was then recorded. The specific unit value was calculated using the equation: $=200 \times\left(\mathrm{A}_{420}\right.$ of the culture $\mathrm{A}_{420}$ in the control tube)/minutes of incubation $\times$ dilution factor.

\section{Quantitative real-time polymerase chain reaction}

RNA was harvested from $B$. subtilis cells in early-log $\left(\mathrm{A}_{600}=0.20-0.40\right)$ with RiboPure ${ }^{\mathrm{Tw}}$ Kit (Ambion), treated with the Turbo DNA-Free $\mathrm{Kit}^{\mathrm{Tm}}$ (Ambion), and reverse transcribed for $1 \mathrm{~h}$ at $42{ }^{\circ} \mathrm{C}$ using the RETROscript ${ }^{\circ} \mathrm{Kit}$ (Ambion). Template was diluted 10-fold, added to iTaq SYBR Green Supermix (Bio-Rad) with appropriate oligonucleotide pairs. Oligonucleotides used in this study are described in (Additional file 11: Table S2). Data were acquired using an Applied Biosystems model 7500 thermocycler. Results were analyzed using the comparative Pfaffl method [54].

\section{Protein purification}

All plasmids encoding genes used for purification were mini-prepped from storage E. coli strain AG1111 and freshly transformed into C41(DE3) cells and consequently used for expression of protein (no frozen stocks were used). Briefly, $1 \mathrm{~L}$ of LB medium was inoculated 1:100 with overnight culture from a single colony. Cells were grown at $37{ }^{\circ} \mathrm{C}$ with the exception of $\mathrm{ClpP}$ and $\mathrm{ClpX}$, which were grown at room temperature. When $\mathrm{A}_{600} \sim 0.6$, cells were induced with isopropyl 1-thio- $\beta-\mathrm{D}-$ galactopyranoside to a final concentration of $1 \mathrm{mM}$. Cells were grown for an additional 4-8 h and then cells were harvested by centrifugation, and cell pellets were stored at $-80{ }^{\circ} \mathrm{C}$. 
$\mathrm{ClpP}$ and ClpX were purified using the IMPACT System (NEB) as described previously [24]. Spx was also purified as previously described [24] with the following modifications: Spx-His was purified from a Ni-NTA column with a 50-500 $\mathrm{mM}$ imidazole gradient and peak fractions pooled. An N-terminal $6 \mathrm{X}-\mathrm{His}$ tag was then removed by cleavage with AcTev protease (Life Technologies). Spx was further purified using size exclusion chromatography over an S-300 column in buffer containing $50 \mathrm{mM}$ Tris $\mathrm{pH} 7.5,50 \mathrm{mM} \mathrm{KCl}$, and $10 \%$ glycerol. Peak fractions were collected, pooled, and concentrated using an Amicon-10 kDa centrifugation column, flash frozen on liquid nitrogen, and stored at $80{ }^{\circ} \mathrm{C}$.

His-UgtP in pET28a(+) (PL3521) was purified as follows: Starting from frozen pellets, cells were thawed on ice and re-suspended in Buffer A $(50 \mathrm{mM}$ Tris $\mathrm{pH} 8.0,500 \mathrm{mM} \mathrm{NaCl}, 10 \mathrm{mM}$ Imidazole, $10 \%$ glycerol). Pefabloc-SC (Sigma) was then added as a protease inhibitor. Re-suspended cells were then lysed by three times by French press at a pressure of 10,000 psi. The lysed cells were then cleared by centrifugation, spinning at $120,000 \times \mathrm{g}$ for $45 \mathrm{~min}$ at $4{ }^{\circ} \mathrm{C}$. The resulting supernatant was brought up to a volume of $50 \mathrm{~mL}$ and loaded onto a DynaLoop connected to a DuoFlow F10 FPLC system (Bio-Rad). The supernatant was then applied over two $5 \mathrm{~mL}$ Bio-Scale Mini Profinity IMAC cartridges connected in series (Bio-Rad). The columns were then washed with 10 column volumes of Buffer A followed by 5 column volumes of Buffer B $(50 \mathrm{mM}$ Tris $\mathrm{pH}$ 8.0, $500 \mathrm{mM} \mathrm{NaCl}, 20 \mathrm{mM}$ Imidazole, 10\% glycerol). Protein was then eluted off of the columns with 5 column volumes of Buffer C (50 mM Tris $\mathrm{pH}$ 8.0, $500 \mathrm{mM} \mathrm{NaCl}, 500 \mathrm{mM}$ Imidazole, $10 \%$ glycerol). Peak fractions were collected and concentrated to a volume of $\sim 1 \mathrm{~mL}$ using an Amicon-10KDa centrifugation column. The concentrated protein was loaded onto a $1 \mathrm{~mL}$ loop and applied over a HiPrep 16/60 Sephacryl S-300 HR size exclusion column (GE Healthcare). The column was washed and protein was then eluted off the column in Buffer D (50 mM HEPES pH 7.5, $100 \mathrm{mM}$ $\mathrm{KCl}, 10 \%$ glycerol). Peak fractions were checked by SDSPAGE and then aliquot, flash frozen on liquid nitrogen and stored at $-80^{\circ} \mathrm{C}$.

\section{In vitro ClpXP proteolysis assay}

Reactions were carried out in $50 \mathrm{mM}$ HEPES pH 7.6, $50 \mathrm{mM} \mathrm{KCl}, 15 \mathrm{mM} \mathrm{Mg}$ acetate, $5 \mathrm{mM}$ DTT, $5 \mathrm{mM}$ ATP, $10 \mathrm{mM}$ creatine phosphate, and $0.1 \mu \mathrm{g} / \mu \mathrm{l}$ creatine kinase (Sigma). $500 \mathrm{ng}$ of His-UgtP was incubated at $37{ }^{\circ} \mathrm{C}$ in the presence of $\mathrm{ClpP}(6 \mu \mathrm{M})$ and $\mathrm{ClpX}$ $(3 \mu \mathrm{M})$ in a $100 \mu \mathrm{l}$ reaction mixture. Each reaction was initiated by the addition of $5 \mathrm{mM}$ ATP. At 0 and
30 or $45 \mathrm{~min}$, samples of the reactions were taken containing what corresponded to $125 \mathrm{ng}$ His-UgtP at the start of the reaction. Samples were then diluted to $2.5 \mathrm{ng} / \mu \mathrm{l}$ with $2 \mathrm{X}$ sample buffer. $50 \mathrm{ng}$ of HisUgtP was then loaded per lane on a 10\% SDS-PAGE. After electrophoresis, proteins were transferred via Western blot to a PVDF membrane. Membranes were blocked, then incubated with mouse monoclonal THE $^{\mathrm{m}}$ His Tag (Genscript) at a 1:4000 dilution overnight at $4{ }^{\circ} \mathrm{C}$. Control reactions with Spx and Thio-His were performed as with His-UgtP except at a concentration of $3 \mu \mathrm{M}$. At 0 and $60 \mathrm{~min}, 15 \mu \mathrm{l}$ of the samples was collected and analyzed on a 15\% SDS-PAGE followed by staining with Coomassie blue.

\section{Fluorescence microscopy and cell length measurements}

Samples were first fixed as previously described [55]. Briefly, cells were fixed by treating with $2.575 \%$ paraformaldehyde and $0.0008 \%$ glutaraldehyde. Fixed samples were permeabilized with $0.01 \mathrm{mg} / \mathrm{mL}$ lysozyme for two minutes, and then treated with $10 \mu \mathrm{g} / \mathrm{mL}$ wheat germ agglutinin tetramethylrhodamine conjugate (WGARhod, ThermoFisher \#W849) in PBS to stain cell wall septa for $10 \mathrm{~min} .5 \mu \mathrm{L}$ of prepared samples were applied to $1 \%$ agarose in PBS pads, allowed to dry, and then covered with a coverslip. Cells were imaged using a Nikon TI-E microscope equipped with a Texas Red/mCherry/ AlexaFluor 594 filter set for fluorescence microscopy (Chroma \# 39010).

Cell length was determined using Nikon Elements by measuring the distance between the midpoints of adjacent cell wall septa for cells stained with WGA-Rhod. Ttest analysis was employed to test for significant differences between conditions.

\section{Lipid extraction}

Bacterial cultures (1 L volumes) were centrifuged at $15,000 \mathrm{x} \mathrm{g}$ for $1 \mathrm{~min}$, decanted, and then resuspended in $100 \mathrm{~mL} 100 \mathrm{mM}$ sodium citrate $\mathrm{pH} 4.7$. Cells were lysed using a French press. Lysates were centrifuged at $12,000 \mathrm{~g}$ for $20 \mathrm{~min}$ to pellet membranes. Pellets were weighed and resuspended to $0.4 \mathrm{~g} / \mathrm{mL}$ in $100 \mathrm{mM}$ sodium citrate $\mathrm{pH}$ 4.7. Methanol and chloroform were added to obtain a ratio of 2:1:0.8 methanol:chloroform:sodium citrate. Mixture was vortexed $30 \mathrm{~s}$ every $15 \mathrm{~min}$ for $2 \mathrm{~h}$. Chloroform and sodium citrate were added to obtain a ratio of 1:1:0.9 methanol:chloroform:sodium citrate. The mixture was vortexed for $1 \mathrm{~min}$ and centrifuged at 4000 $\mathrm{x} \mathrm{g}$ for $10 \mathrm{~min}$. Bottom chloroform layer was transferred to a new tube. Methanol and sodium citrate were added to obtain a ratio of 1:1:0.9 methanol: chloroform:sodium citrate. Mixture was vortexed for $1 \mathrm{~min}$ and centrifuged at $4000 \mathrm{x} \mathrm{g}$ for $10 \mathrm{~min}$. 
Bottom chloroform layer was transferred to new tube and allowed to dry in fume hood. Dried lipids were weighed and resuspended in 1:1 methanol:chloroform to a final concentration of $600 \mathrm{mg} / \mathrm{mL}$ and stored at $-20^{\circ} \mathrm{C}$.

\section{Lipid thin-layer chromatography and diglucosyl-diacylglycerol quantification}

$140 \mathrm{~mL}$ chloroform and $60 \mathrm{~mL}$ methanol were added to a glass TLC development chamber. Placed filter paper into developing solution, thoroughly wetted blot paper, and then placed the paper along the chamber walls. A TLC plate (Analtech \#p46021) was pre-run in developing solution by placing it in the chamber, covering the chamber with its glass lid, and allowing the solvent to run to the top of the plate. The plate was dried at $100{ }^{\circ} \mathrm{C}$ for $10 \mathrm{~min}$. Using a pencil, a line was drawn across the width of the plate approximately $1 \mathrm{~cm}$ from the bottom. Lipid samples $(2 \mu \mathrm{L})$ were spotted along this line and allowed to dry. Samples were repeatedly spotted and allowed to dry 5 additional times. Once the spots were dry, the plate was placed back into the chamber, the lid was placed on top, and the solvent was allowed to run to $1 \mathrm{~cm}$ from the top of the plate. The plate was taken out of the development chamber, the solvent line was quickly marked with pencil, and the plate was dried. The plate was then placed inside a polystyrene container with a few iodine crystals, sealed, and stained for $16 \mathrm{~h}$ with iodine gas. The stained plate was scanned to acquire images. The stained plate was scanned to acquire images. ImageJ was used to quantify the amount of DGD present, and another band (indicated in Additional file 8: Figure S8) was used as a loading control. T-test analysis was employed to test for significant differences between conditions.

\section{Statistical analysis}

Statistical parameters and significance are reported in the figures and the figure legends. Asterisks designate statistical significance as: *, $p<0.05$; **, $p<0.01$; ***, $p<$ $0.001 ; * * * * *, p<0.0001$. Statistical analysis was performed in GraphPad PRISM 6.

\section{Additional files}

Additional file 1: Figure S1. YFP-UgtP is degraded in minimal sorbitol; this file shows ectopically expressed YFP-UgtP cultured in nutrient-rich and nutrient-poor media. (PDF $817 \mathrm{~kb}$ )

Additional file 2: Figure S2. Representative immunoblot for in vivo UgtP degradation experiment; this file shows an immunoblot of UgtP-His from cells with and without $\mathrm{ClpP}$, cultured in nutrient-poor media over a 2-h period, after addition of spectinomycin. (PDF $967 \mathrm{~kb}$ )

Additional file 3: Figure S3. UgtP oligomer mutant has WT localization and delays cell division in a $\triangle p g c A$ background; this file shows immunofluorescence images of cells harboring either yfp-ugtP or yfpugtP ${ }^{\mathrm{OLI}-}$ in a UDP-glucose null background cultured in nutrient-rich media, and also shows cell length distributions for the previously mentioned strains. (PDF $278 \mathrm{~kb}$ )
Additional file 4: Figure S4. ugt $P^{\text {HEX }}$-his is expressed the same level as WT and UgtP ${ }^{H E X}{ }^{-}$-His is stabilized in a $\triangle c l p P$ background; this file shows qRT-PCR data for ugtP binding mutants compared to WT ugtP, and also shows semi-quantitative immunoblots for UgtP-His from the previously mentioned strains cultured in both nutrient-rich and nutrient-poor media. (PDF $220 \mathrm{~kb}$ )

Additional file 5: Figure S5. A comparison of UDP-glucose molecules per cell during growth in LB and minimal sorbitol; this file shows UDPglucose molecules per cell from WT, $\Delta p g c A$, and $\Delta u g t P$ cells cultured in nutrient-rich media (and WT in nutrient-poor media) as measured by LCMS/MS. (PDF $112 \mathrm{~kb}$ )

Additional file 6: Figure S6. Positive and negative controls for the ClpXP in vitro proteolysis assay; this file shows proteolysis of both a known substrate for ClpXP (Spx), and a non-targeted protein (Thioredoxin-His). (PDF $117 \mathrm{~kb}$ )

Additional file 7: Figure S7. UgtP concentration can be modulated in minimal sorbitol; this file shows semi-quantitative immunoblots for UgtPHis from strains containing either one inducible copy of ugtP-his, or one inducible copy and one "native" copy of ugtP-his, cultured in nutrientpoor media. (PDF $175 \mathrm{~kb}$ )

Additional file 8: Figure S8. Representative TLC of membrane lipids, including diglucosyl-diacylglycerol; this file shows lipid extracts from strains producing variable amounts of UgtP cultured in nutrient-poor media, separated on a TLC plate. (PDF $6249 \mathrm{~kb}$ )

Additional file 9: Supplemental Methods and References. Methods and references for the experiments performed in (Additional file 1: Figure S1, Additional file 2: Figure S2, Additional file 3: Figure S3, Additional file 4: Figure S4, Additional file 5: Figure S5, Additional file 6: Figure S6, Additional file 7: Figure S7, Additional file 8: Figure S8). (DOCX $23 \mathrm{~kb}$ )

Additional file 10: Table S1. Bacterial strains used in this study; this file contains a table of strains, their genotypes, and their sources used in this study. (DOCX 26 kb)

Additional file 11: Table S2. Oligonucleotide sequences used for qRT$\mathrm{PCR}$; this file contains a table of the oligonucleotide sequences used for qRT-PCR of various genes. (DOCX $53 \mathrm{~kb}$ )

\section{Abbreviations}

DGD: Diglucosyl-diacylglycerol; LB: Lysogeny Broth; LTA: Lipoteichoic Acid; Minimal Glucose: $\mathbf{S 7} 7_{50}+1 \%$ Glucose; Minimal Glycerol: $\mathbf{S 7} 7_{50}+1 \%$ Glycerol; Minimal Sorbitol: $\mathbf{S}_{50}+1 \%$ Sorbitol; OPG: Osmoregulated Periplasmic Glucan

\section{Acknowledgements}

We are indebted to Richard Losick, Peter Zuber, and David Dubnau for the kind gift of strains and reagents. We thank EKB, MAH, OJB, and RSM for their critical reading. Finally, we thank all members of the Levin lab for thoughtful discussions. This work was supported by a National Institutes of Health grant (NIH GM64671) to PAL.

\section{Funding}

This work was supported by a National Institutes of Health grant $(\mathrm{NIH}$ GM64671) to PAL. The funding agency had no role in design of this study, collection, analysis, and interpretation of data, nor writing of this manuscript.

Availability of data and methods

The datasets used and/or analyzed during the current study are available from the corresponding author on reasonable request.

\section{Authors contributions}

$\mathrm{NH}$ designed and performed all aspects of the experimentation except as noted below, analyzed data, and drafted the manuscript. JZ performed and analyzed data for the in vivo UgtP-His proteolysis assay in (Fig. 3C), cell measurements and membrane lipid TLC in (Fig. 6 and Table 1), Western blots of YFP-UgtP in (Additional file 1: Figure S1), Western blots to demonstrate differences in UgtP-His expression in (Additional file 7: Figure S7). JZ also designed the cell measurement experiment in (Fig. 6A and Table 1) and assisted in drafting the manuscript. PB performed, designed, and analyzed the in vitro His-UgtP proteolysis assay in (Fig. 5 and Additional file 6: Figure S6) including the purification of ClpXP and UgtP. PB also assisted in drafting 
the manuscript. AC constructed the hexose/uracil/oligomerization mutant forms of ugtP used in (Fig. 4 and Additional file 4: Figure S4). PAL helped design experiments and draft the manuscript. All authors read and approved the final manuscript.

\section{Ethics approval and consent to participate}

Not Applicable.

\section{Consent for publication}

Not Applicable.

\section{Competing interests}

The authors declare that they have no competing interests.

\section{Publisher's Note}

Springer Nature remains neutral with regard to jurisdictional claims in published maps and institutional affiliations.

\section{Author details}

${ }^{1}$ Department of Biology, Washington University, St. Louis 63130, MO, USA 2Present address: Department of Molecular and Cell Biology, University of California, Berkeley 94720, CA, USA. ${ }^{3}$ Present address: Department of Bacteriology, University of Wisconsin, Madison 53706, WI, USA. ${ }^{4}$ Present address: Clinical Immunology and Bioanalysis, Medlmmune LLC, South San Francisco 94080, CA, USA. 'Leukaemia \& Blood Cancer Research Unit, University of Auckland, Private Bag 92019, Auckland 1142, New Zealand.

\section{Received: 15 August 2017 Accepted: 8 February 2018}

\section{Published online: 06 April 2018}

\section{References}

1. Schaechter M, Maaløe O, Kjeldgaard NO. Dependency on medium and temperature of cell size and chemical composition during balanced grown of Salmonella typhimurium. J Gen Microbiol. 1958;19:592-606.

2. Sargent MG. Control of cell length in Bacillus subtilis. J Bacteriol. 1975; 123:7-19.

3. Pierucci O. Dimensions of Escherichia coli at various growth rates: model for envelope growth. J Bacteriol. 1978;135:559-74

4. Weart RB, Lee AH, Chien A-C, Haeusser DP, Hill NS, Levin PA. A metabolic sensor governing cell size in bacteria. Cell. 2007;130:335-47.

5. Hill NS, Buske PJ, Shi Y, Levin PA. A moonlighting enzyme links Escherichid coli cell size with central metabolism. PLoS Genet. 2013;9:e1003663.

6. Vadia S, Levin PA. Growth rate and cell size: a re-examination of the growth law. Curr Opin Microbiol. 2015;24:96-103.

7. Potrykus K, Murphy H, Philippe N, Cashel M. ppGpp is the major source of growth rate control in E. coli. Environ Microbiol. 2011;13:563-75.

8. Dalebroux ZD, Swanson MS. ppGpp: magic beyond RNA polymerase. Nat Rev Microbiol. 2012;10:203-12.

9. Ehrenberg M, Bremer $\mathrm{H}$, Dennis PP. Medium-dependent control of the bacterial growth rate. Biochimie. 2013;95:643-58.

10. Gerth U, Kock H, Kusters I, Michalik S, Switzer RL, Hecker M. Clp-dependent proteolysis down-regulates central metabolic pathways in glucose-starved Bacillus subtilis. J Bacteriol. 2008;190:321-31.

11. Battesti A, Majdalani N, Gottesman S. The RpoS-mediated general stress response in Escherichia coli. Annu Rev Microbiol. 2011;65:189-213.

12. Price $K D$, Roels $S$, Losick R. A Bacillus subtilis gene encoding a protein similar to nucleotide sugar transferases influences cell shape and viability. J Bacteriol. 1997;179:4959-61.

13. Kennedy EP, Rumley MK. Osmotic regulation of biosynthesis of membranederived oligosaccharides in Escherichia coli. J Bacteriol. 1988;170:2457-61.

14. Jorasch P, Wolter FP, Zahringer U, Heinz E. A UDP glucosyltransferase from Bacillus Subtilis successively transfers up to four glucose residues to 1,2diacylglycerol: expression of ypfP in Escherichia coli and structural analysis of its reaction products. Mol Microbiol. 1998;29:419-30.

15. Therisod H, Weissborn AC, Kennedy EP. An essential function for acyl carrier protein in the biosynthesis of membrane-derived oligosaccharides of Escherichia coli. P Natl Acad Sci USA. 1986;83:7236-40.

16. Percy $M G$, Gründling A. Lipoteichoic acid synthesis and function in grampositive bacteria. Annu Rev Microbiol. 2014;68:81-100.

17. Reichmann NT, Piçarra Cassona C, Monteiro JM, Bottomley AL, Corrigan RM, Foster SJ, et al. Differential localization of LTA synthesis proteins and their interaction with the cell division machinery in Staphylococcus aureus. Mol Microbiol. 2014:92:273-86.

18. Matias VRF, Beveridge TJ. Lipoteichoic acid is a major component of the Bacillus subtilis periplasm. J Bacteriol American Society for Microbiology. 2008;190:7414-8.

19. Lazarevic V, Soldo B, Medico N, Pooley H, Bron S, Karamata D. Bacillus subtilis Alpha-phosphoglucomutase is required for normal cell morphology and biofilm formation. Appl Environ Microbiol. 2005;71:39-45.

20. Chien A-C, Zareh SKG, Wang YM, Levin PA. Changes in the oligomerization potential of the division inhibitor UgtP co-ordinate Bacillus subtilis cell size with nutrient availability. Mol Microbiol. 2012;86:594-610.

21. Weart RB, Levin PA. Growth rate-dependent regulation of medial FtsZ ring formation. J Bacteriol. 2003;185:2826-34.

22. Feucht A, Lucet I, Yudkin MD, Errington J. Cytological and biochemical characterization of the FtsA cell division protein of Bacillus subtilis. Mol Microbiol. 2001;40:115-25.

23. Haeusser DP, Lee AH, Weart RB, Levin PA. ClpX inhibits FtsZ assembly in a manner that does not require its ATP hydrolysis-dependent chaperone activity. J Bacteriol. 2009:191:1986-91.

24. Weart RB, Nakano S, Lane BE, Zuber P, Levin PA. The ClpX chaperone modulates assembly of the tubulin-like protein FtsZ. Mol Microbiol. 2005:57:238-49.

25. Baker TA, Sauer RT. ClpXP, an ATP-powered unfolding and proteindegradation machine. Biochim Biophys. 2012;1823:15-28.

26. Kress W, Maglica Z, Weber-Ban E. Clp chaperone-proteases: structure and function. Res Microbiol. 2009;160:618-28.

27. Camberg JL, Hoskins JR, Wickner S. ClpXP protease degrades the cytoskeletal protein, FtsZ, and modulates FtsZ polymer dynamics. P Nat Acad Sci USA. 2009;106:10614-9.

28. Botté C, Jeanneau C, Snajdrova L, Bastien O, Imberty A, Breton C, et al. Molecular modeling and site-directed mutagenesis of plant chloroplast monogalactosyldiacylglycerol synthase reveal critical residues for activity. J Biol Chem. 2005:280:34691-701.

29. Gerth U, Kirstein J, Mostertz J, Waldminghaus T, Miethke M, Kock H, et al. Fine-tuning in regulation of Clp protein content in Bacillus subtilis. J Bacteriol. 2004;186:179-91.

30. Nakano S, Zheng G, Nakano MM, Zuber P. Multiple pathways of Spx (YjbD) proteolysis in Bacillus subtilis. J Bacteriol. 2002;184:3664-70.

31. Turgay K, Hahn J, Burghoorn J, Dubnau D. Competence in Bacillus subtilis is controlled by regulated proteolysis of a transcription factor. EMBO J. 1998; 17:6730-8.

32. Pan $\mathrm{Q}$, Garsin DA, Losick R. Self-reinforcing activation of a cell-specific transcription factor by proteolysis of an anti-sigma factor in B. subtilis. Mol Cell. 2001:8:873-83.

33. Zhou Y, Gottesman S, Hoskins JR, Maurizi MR, Wickner S. The RssB response regulator directly targets sigma(S) for degradation by ClpXP. Genes Dev. 2001;15:627-37.

34. Langklotz S, Narberhaus F. The Escherichia coli replication inhibitor CspD is subject to growth-regulated degradation by the Lon protease. Mol Microbiol. 2011:80:1313-25.

35. Schäkermann M, Langklotz S, Narberhaus F. FtsH-mediated coordination of lipopolysaccharide biosynthesis in Escherichia coli correlates with the growth rate and the alarmone (p)ppGpp. J Bacteriol. 2013;195(9):1912.

36. Buczek MS, Cardenas Arevalo AL, Janakiraman A. ClpXP and ClpAP control the Escherichia coli division protein ZapC by proteolysis. Microbiology. 2016; 162:909-20.

37. Sauer RT, Baker TA. AAA+ proteases: ATP-fueled machines of protein destruction. Annu Rev Biochem. 2011:80:587-612.

38. Elsholz AKW, Birk MS, Charpentier E, Turgay K. Functional diversity of AAA+ protease complexes in Bacillus subtilis. Front Mol Biosci. 2017:4:44.

39. Kirstein J, Dougan DA, Gerth U, Hecker M, Turgay K. The tyrosine kinase McsB is a regulated adaptor protein for ClpCP. EMBO J. 2007:26:2061-70.

40. Persuh M, Mandic-Mulec I, Dubnau D. A MecA paralog, YpbH, binds ClpC, affecting both competence and sporulation. J Bacteriol. 2002:184:2310-3.

41. Schlothauer T, Mogk A, Dougan DA, Bukau B, Turgay K. MecA, an adaptor protein necessary for ClpC chaperone activity. P Natl Acad Sci USA. 2003; 100:2306-11.

42. Pan $\mathrm{Q}$ Losick R. Unique degradation signal for ClpCP in Bacillus subtilis. J Bacteriol. 2003;185:5275-8.

43. Wiegert T, Schumann W. SsrA-mediated tagging in Bacillus subtilis. J Bacteriol. 2001;183:3885-9. 
44. Salahudeen AA, Thompson JW, Ruiz JC, Ma H-W, Kinch LN, Li Q, et al. An E3 ligase possessing an iron-responsive hemerythrin domain is a regulator of iron homeostasis. Science. 2009;326:722-6.

45. Zhu J, Winans SC. The quorum-sensing transcriptional regulator TraR requires its cognate signaling ligand for protein folding, protease resistance, and dimerization. P Natl Acad Sci USA. 2001;98:1507-12.

46. Vashisht AA, Zumbrennen KB, Huang X, Powers DN, Durazo A, Sun D, et al. Control of iron homeostasis by an iron-regulated ubiquitin ligase. Science. 2009:326:718-21.

47. Hecker M. A proteomic view of cell physiology of Bacillus subtilis-bringing the genome sequence to life. Adv Biochem Eng Biotechnol. 2003;83:57-92.

48. Perego M, Spiegelman GB, Hoch JA. Structure of the gene for the transition state regulator, abrB: regulator synthesis is controlled by the $5 p 00 \mathrm{~A}$ sporulation gene in Bacillus subtilis. Mol Microbiol. 1988;2:689-99.

49. Ireton K, Rudner DZ, Siranosian KJ, Grossman AD. Integration of multiple developmental signals in Bacillus subtilis through the SpoOA transcription factor. Genes Dev. 1993;7:283-94.

50. Jaacks KJ, Healy J, Losick R, Grossman AD. Identification and characterization of genes controlled by the sporulation-regulatory gene spoOH in Bacillus subtilis. J Bacteriol. 1989;171:4121-9.

51. Arjes HA, Lai B, Emelue E, Steinbach A, Levin PA. Mutations in the bacterial cell division protein FtsZ highlight the role of GTP binding and longitudinal subunit interactions in assembly and function. BMC Microbiol. 2015;15:209.

52. Hill NS, Kadoya R, Chattoraj DK, Levin PA. Cell size and the initiation of DNA replication in bacteria. PLoS Genet. 2012;8:e1002549.

53. Zhang $\mathrm{X}$, Bremer $\mathrm{H}$. Control of the Escherichia coli rrnB P1 promoter strength by ppGpp. J Biol Chem. 1995;270:11181-9.

54. Pfaffl MW. A new mathematical model for relative quantification in real-time RT-PCR. Nucleic Acids Res. 2001;29:e45.

55. Levin PA. Light Microscopy Techniques for Bacterial Cell Biology. In: Sansonetti PJ, Zychlinsky A, editors. Molecular Cellular Microbiology. 2002. pp. 115-32.

\section{Submit your next manuscript to BioMed Central and we will help you at every step:}

- We accept pre-submission inquiries

- Our selector tool helps you to find the most relevant journal

- We provide round the clock customer support

- Convenient online submission

- Thorough peer review

- Inclusion in PubMed and all major indexing services

- Maximum visibility for your research

Submit your manuscript at www.biomedcentral.com/submit

) Biomed Central 